\title{
La tradición norteamericana en José Martí entre filosofía y literatura
}

\author{
María Fernanda PAMPÍN \\ Universidad de Buenos Aires / Consejo Nacional de Investigaciones Científicas y Técnica \\ mfpampin@gmail.com
}

\begin{abstract}
RESUMEN
Las relaciones culturales entre Cuba y los Estados Unidos han sido muy productivas desde el siglo XIX. La cercanía del gran país del norte, con su poderío económico y cultural, ha sido indudablemente un núcleo generador de sentidos. A partir de estas cuestiones, este trabajo se propone relevar los intereses martianos en la literatura y la filosofía norteamericanas, un aspecto desdeñado por el latinoamericanismo clásico. En este sentido, se recoloca la obra de José Martí en el centro del canon occidental decimonónico, estableciendo un diálogo productivo entre Ralph Emerson, Walt Whitman y Martí que permita indagar, complejizar y reconsiderar el peso que tuvo una tradición de origen anglosajón en la construcción de la literatura y el pensamiento martiano.
\end{abstract}

Palabras clave: José Martí, literatura cubana, trascendentalismo, filosofía vs. literatura, Walt Whitman, Ralph W. Emerson.

The American tradition in José Martí between philosophy and literature

\begin{abstract}
Cultural relationships between Cuba and the United States have been very productive since the Nineteenth Century. Without hesitation, the proximity of Cuba to the great North Country has been a core generator of senses. According to these issues, this paper proposes tracing Marti interest in American philosophy and literature, a neglected aspect by classical Latino Americanism. In this sense, it plans to relocate the work of Martí in the center of nineteenth-century Western canon, establishing a dialogue between Ralph Emerson, Walt Whitman and Martí. This dialogue allows exploring, complicating and reconsidering the weight that had Anglo-Saxon tradition in the construction of Marti's literature and thought.
\end{abstract}

Key words: José Martí, Cuban literature, transcendentalism, philosophy vs. literature, Walt Whitman, Ralph W. Emerson.

Existe un antiguo y perdurable vínculo establecido entre la literatura cubana y la norteamericana desde los inicios del siglo XIX. Las relaciones culturales entre Cuba y los Estados Unidos han sido muy productivas desde entonces. La cercanía del 
gran país del norte, con su poderío económico y cultural, ha sido indudablemente un núcleo generador de sentidos. Estas relaciones requirieron, no obstante, de un desarrollo más profundo desde un enfoque que revalorizó la productividad real de esos nexos. Nos referimos a la línea intelectual que llegó hasta José Martí y que va desde Domingo del Monte y Juan Clemente Zenea hasta Enrique Piñeyro.

A partir de estas cuestiones, nos hemos propuesto, en trabajos anteriores (Pampín 2015a; Pampín 2015b), relevar los intereses martianos en la cultura y literatura norteamericana pero también plantear con Iván Schulman (2001) la necesidad de leer a Martí en el contexto de esa literatura.

La propia relación de Martí con la tradición literaria y cultural estadounidense es anterior a su estadía neoyorquina ya que durante su período de formación intelectual en la isla y sus primeros viajes por América Latina adquirió un conocimiento sumamente amplio de las corrientes literarias, los pensadores y las manifestaciones culturales ${ }^{1}$.

Sin embargo, es durante su estadía en los Estados Unidos, cuando José Martí establece vínculos entre el hombre, la naturaleza y la historia en sus producciones a partir de un concepto clave: el de "hombre natural" que retoma del discurso filosófico de Ralph W. Emerson.

Durante el siglo XIX, a raíz de su largo exilio neoyorquino, José Martí fue uno de los intelectuales hispanoamericanos que conoció más de cerca el campo cultural y político norteamericano. Si bien ese período ha sido muy estudiado, el carácter decisivo que tuvo el encuentro de Martí con el trascendentalismo y su consecuente apropiación y resignificación del discurso de Emerson ha sido un aspecto poco atendido. El análisis de esta cuestión, por una parte, permite relevar su importancia orientadora en relación con sus objetivos estéticos y políticos en el momento de escritura que tiene como punto de partida a Ismaelillo. Por otra, conocer el modo en que Martí recupera la tradición norteamericana permite redimensionar el carácter de los vínculos que establece en ese mismo momento con otros autores cubanos y latinoamericanos del siglo XIX.

${ }^{1}$ Es probable que en las tertulias organizadas por su maestro Mendive, gran conocedor de la literatura norteamericana del siglo XIX, haya escuchado referencias acerca de la presencia de Emerson y de otros autores norteamericanos en figuras de la literatura cubana como José de la Luz y Caballero, Juan Clemente Zenea, Néstor Ponce de León y el propio Mendive (Cruz 1982: 78). Mary Cruz presume que Martí pudo leer la reseña de Ponce de León publicada en la Revista de Ciencias y Artes en 1868 sobre ediciones de la obra de Emerson y señala el uso de Martí, quizás por casualidad, de imágenes que, como la del águila, ya aparecen en el texto de Ponce. Por lo demás, es posible asegurar también que Martí llegó a conocer la conferencia que Enrique José Varona (1936) dedicó a Emerson ya que fue comentada en una reseña publicada en El Economista Americano de Nueva York en 1888 . 
A raíz de su desembarco en la gran ciudad de la modernidad, señala Ángel Rama, Martí no solo profundiza en la obra de Emerson sino que realiza un viraje fundamental en su pensamiento filosófico (que asimismo, añadimos, se produjo en sus presupuestos estéticos). De este modo, explica:

hay una circunstancia que para nosotros divide la obra de Martí en dos épocas precisas: su asimilación del pensamiento norteamericano a partir de 1880. Su obra anterior, con todos sus atisbos, carece de la sazonada claridad de pensamiento que adquiere a partir de esa fecha (Rama 2015c: 24).

La tradición anglosajona en Martí no ha sido hasta el momento trabajada con suficiente profundidad por la crítica especializada. En las últimas décadas han surgido estudios específicos que lo vinculan con esa tradición: los encarados por Mary Cruz (1978, 1982, 1988, 1983 y 1995-1996), Anne Fountain (2003a, 2003b y 2012), José Ballón (1986 y 2013) y Ana Cairo (2003), que, si bien no se ocupan del tema específico de este trabajo, se constituyen en aportes que permiten conocer los intereses martianos por esa cultura.

Nos interesa, por este motivo, abordar las relaciones de Martí con el campo cultural norteamericano para centrar la atención en los autores vinculados de algún modo al círculo intelectual trascendentalista con el propósito de hallar puntos de contacto y establecer zonas de debate. Este estudio se realizará, en relación a las obras de Ralph Emerson y Walt Whitman, autores que iniciaron nuevos recorridos intelectuales y marcaron un giro que podría calificarse de inédito en el ámbito filosófico y estético en la obra de Martí. Esto permitirá mostrar de qué modo esta nueva manera de pensar produce un quiebre del sistema tanto literario como filosófico en Cuba -y que, sin un esfuerzo especial, podría ampliarse también a Latinoamérica-, basado en ese momento en una tradición de origen predominantemente francés.

La lectura de la obra de Emerson fue, sin lugar a dudas, un suceso muy significativo en la vida y en la obra de Martí. Cuando llega a Nueva York, Emerson ya era un escritor de setenta y siete años (moriría dos años más tarde) que, por ser reconocido como poeta y pensador en los círculos literarios y académicos desde hacía décadas, había logrado situarse en el centro del canon norteamericano. La circulación de sus libros se extendía por las ciudades más importantes del país, su nombre aparecía con frecuencia en los periódicos norteamericanos y aunque ya no las ofrecía, sus prestigiosas conferencias eran muy bien recordadas por un público lector que lo reconocía. Sostiene José Ballón: "Más que faro Emerson fue chispa encendedora. Al mismo tiempo de descubrir en él una cosmovisión afín, vio propulsada su propia reflexión metalingüística y llegó a dar forma a las premisas centrales de su teoría poética" (1995: 29). El hallazgo de su obra, la profundización en su pensamiento, que significó al mismo tiempo el descubrimiento y el encuentro de otros autores norteamericanos, le permitió reorientar su pensamiento en términos 
no solo filosóficos sino también estéticos, políticos y culturales con el propósito específico y evidente de atender a una preocupación central en sus reflexiones, aquello que Rama ha denominado "la incorporación de la América hispana a la modernidad" (2015c: 28).

La reunión y conexión de los términos discurso filosófico y literatura ha sido para nosotros una preocupación constante en el momento de pensar la obra martiana y el concepto de hombre natural que en ella se representa. Esta preocupación, que se concentra en la literatura, refiere a una metodología de análisis, a un modo de acercarse al problema, más que a la polémica que resulta de la competencia entre dos campos de estudio. Como sostienen Philippe Lacoue-Labarthe y Jean-Luc Nancy "el hecho de que la literatura vea su destino ligado a ese breve texto de la filosofía en el que, desde Platón a Aristóteles por lo menos, se postula y exige la unión entre la poesía y la filosofía" (2012: 36, énfasis en el original $)^{2}$, no es un problema nuevo. Debido a que, en el ámbito de los estudios académicos, se las suele considerar de manera independiente, la propuesta de su vinculación ha facilitado en este trabajo el acercamiento a un problema de antigua tradición. La historia del latinoamericanismo clásico, en su afán reduccionista, ha desdeñado el análisis de esta faceta del pensamiento martiano, tan importante como su conexión con los predecesores y contemporáneos anglosajones (en especial los norteamericanos). En esa postura, que privilegió la relación con el pensamiento cubano, el de Martí se constituyó en un predominio ligado a las voces del Presbítero Félix Varela, José de la Luz y Caballero o de Antonio Saco. Sin desmerecer en absoluto la importancia de esta vertiente, habrá que reconocer que no se constituye en la única opción posible en relación con la configuración del pensamiento martiano. Esta perspectiva se evidencia, sin un esfuerzo especial, en las lecturas producidas desde la isla en la medida en que se "ajustan" al discurso latinoamericanista clásico que entiende el latinoamericanismo como antiimperialismo, como puede verse en un libro de reciente aparición de Pablo Guadarrama González (2014), uno de los más importantes especialistas en el discurso filosófico martiano ${ }^{3}$.

Esto mismo resulta evidente en la historia de las ideas en América Latina donde el nombre de Martí tiene un lugar indiscutible junto a los nombres vinculados principalmente a las luchas por las independencias americanas y sus causas: José de San Martín, Simón Bolívar, Bernardo O'Higgins, Francisco de Miranda o José Gervasio Artigas, mientras que, en otra serie diferente y simultánea, se lo inscribe entre los representantes de la República de las Letras: Eugenio María de Hostos,

${ }^{2}$ Los autores remiten a una cita de Friedrich Schlegel en el fragmento 115 del Atheneum que analizaremos más adelante.

${ }^{3}$ Pese a ello, el autor reconoce en la obra de Martí, sin embargo, ciertas resonancias emersonianas. 
Andrés Bello, Domingo F. Sarmiento, Juan B. Alberdi, entre muchos otros. No obstante esto, las lecturas de Martí y el consiguiente recorrido propuesto por sus obras muestran un interés creciente en el campo intelectual norteamericano y trazan un recorrido alternativo que no anula el ya conocido por el latinoamericanismo y el pensamiento clásico latinoamericano sino que ponen en evidencia otras vertientes y caminos que no sería adecuado ignorar en el momento de considerar una historia intelectual en América Latina.

Como es sabido, en los escritos martianos es posible leer los aportes de diferentes doctrinas que contribuyeron a conformar su propio discurso, autónomo y original. Esas contribuciones surgen de filosofías tan disímiles como el krausismo, el cristianismo, el positivismo, el romanticismo y el trascendentalismo, que nos conduce directamente hacia la obra de Emerson ${ }^{4}$.

No es el propósito de este trabajo restar originalidad a las reflexiones martianas sino, por el contrario, trazar una coordenada intelectual de la que Martí se nutrió desde fines del siglo XVIII y comienzos del XIX para formar su propio pensamiento y en la que procuramos incluirlo ya que, a lo largo de su compleja y vasta recepción crítica, se ha considerado la filosofía martiana exclusivamente en el contexto latinoamericano sin prestar debida atención a las diferentes culturas que aprehendió, una cuestión que, en consecuencia, termina empobreciendo su lectura. Pretendemos así mostrar que la figura de Martí y la de Emerson en tanto intelectuales, se encuentran insertas en un complejo campo cultural, mucho más amplio de lo que suele reconocerse.

Es por eso que, con Fornet-Betancourt (1995), planteamos que la literatura martiana se sostiene en una filosofía comprometida, polifónica (en el sentido de que incorpora luego las voces de indios, negros, criollos, etc., como se puede apreciar en los Diarios) e intercultural (abierta a diversos aportes). Esta apelación al universalismo cultural para Latinoamérica no es exclusiva de Martí, también puede percibirse en otros intelectuales. Tiene como propósito esencial, como explica Rama (2015b), combatir el imperialismo de la cultura francesa en un momento determinado, lo que, desde ya, implica una apertura que se explica mediante la irrupción de otras presencias culturales: básicamente, la inglesa, la alemana y la norteamericana. El resultado es la hibridez característica en las producciones de nuestro continente.

Entendemos, en términos de Pablo Guadarrama González (1995), que el propósito de Martí consistía en utilizar la teoría (comprendida aquí como aquellos núcleos productivos y ejes conceptuales fundamentales retomados del discurso trascendentalista de Emerson) para "moldear" al hombre, así, en el marco de esta

${ }^{4}$ Algunos de esos aportes pueden verse en Ottmar Ette y Titus Heydenreich (Ed.), José Martí 1895-1995. Literatura-Política-Filosofia-Estética (1995). 
línea argumentativa, la teoría es llevada por Martí a la práctica, "materializada", tal como podrá apreciarse en los Diarios. En idéntico sentido, Raúl Fornet-Betancourt (1995) sostiene que existe una "praxis" de la filosofia y que esa perspectiva, transformada de inmediato en metodología, construye un nuevo modo de producir filosofía. Resulta, por lo tanto, inevitable regresar a las palabras de Arturo Roig en su clásico ensayo Teoría y crítica del pensamiento latinoamericano: "sucede que la filosofía es una práctica" (2009: 11).

A la luz de estas cuestiones, es posible y necesario interrogarse en qué medida se apropia Martí del discurso emersoniano. Al mismo tiempo es factible plantear otra pregunta: ¿posee la filosofía un poder transformador de la realidad? Si así fuere, ¿tiene la capacidad de ofrecer soluciones a problemas concretos y, en este caso, contribuir desde el ámbito teórico a la liberación del hombre y a estrechar su vínculo con la naturaleza?

La relación que Martí entabla con los diversos discursos filosóficos no se apoya en un mero interés erudito de instruir a su público sino que tiene su centro más bien en un examen crítico orientado a esclarecer cómo la filosofía se hace cargo de la vida y de la historia humana. En su relación con la filosofía a Martí le interesa menos la historia de la filosofía que distinguir la función de la filosofía en la historia. De este modo, pretende comprender si la filosofía es capaz de hacer un aporte a los procesos de cambios históricos a favor de los sectores sociales oprimidos (Fornet-Betancourt 1995: 45-46).

Martí representa el equilibrio entre corrientes espiritualistas como el idealismo o el trascendentalismo y materialistas, como el empirismo o cientificismo. Así sostiene con gran frecuencia en sus cuadernos de apuntes:

La naturaleza observable es la única fuente filosófica.

El hombre observador es el único agente de la Filosofía.

Pero hay dos clases de seres: los que se tocan y los que no se pueden tocar. [...] Lo que se puede tocar se llama tangible, y lo que no puede probarse a la vista, evidente. Lo que no se puede tocar ni ver es invisible e intangible. [...] Al estudio del mundo tangible, se ha llamado física; y al estudio del mundo intangible, metafísica.

La exageración de aquella escuela se llama materialismo; y corre con el nombre de espiritualismo, aunque no debe llamarse así, la exageración de la segunda. [...] Las dos unidas son la verdad: cada una aislada es sólo una parte de la verdad, que cae cuando no se ayuda de la otra (O.C. 20:360-361).

Para Martí, como para Emerson, solamente la observación de la naturaleza puede responder a preguntas del orden filosófico.

A partir de estas reflexiones, Martí propuso "fundar la literatura en la ciencia", de allí que no aspire a "introducir el estilo y el lenguaje científicos en la literatura, que es una forma de la verdad distinta de la ciencia, sino comparar, imaginar, aludir y deducir de modo que lo que se escriba permanezca, por estar en acuerdo con los 
hechos constantes y reales" (O.C. 22 1991: 141, el subrayado es del autor). Esta idea, que entiende la literatura como vía epistemológica, se corresponde más "a la cercana influencia del trascendentalismo de Emerson o del panteísmo de Whitman, ejemplos de un ambicioso esfuerzo unificante de la multiplicidad aparencial" que a los grandes modelos románticos de Shelley o de Victor Hugo (Rama 2015b: 97).

En sus escritos resuenan no solo ecos emersonianos y whitmanianos sino que se presupone irrefutable el romanticismo alemán. En el recordado fragmento 115 de Friedrich Schlegel (1797) se halla expresado el programa del Athenaeum: "Toda la historia de la poesía moderna es un comentario continuo al breve texto de la filosofía: todo arte debe devenir ciencia y toda ciencia arte. La poesía y la filosofía deben estar unidas" (Lacoue-Labarthe y Nancy 2012: 129).

En la propia literatura norteamericana del siglo XIX, los vínculos entre filosofía y literatura son demasiado fuertes para separar ambos campos de estudio. Las producciones se encuentran, a menudo, desbordando los límites, las exigencias y las prácticas que los discursos imponen. En última instancia, esa intensa comunicación entre filosofía y literatura en la que se basa esta investigación, es como sostiene Stanley Cavell, "algo que provoca el romanticismo" (2002: 88) y de allí deriva, quizás, una enorme parte de la estrecha relación entre el trascendentalismo norteamericano y el romanticismo europeo (alemán e inglés).

Sin embargo, los especialistas en el área no terminan en acordar acerca del reconocimiento del trascendentalismo como corriente filosófica por lo que consideran a Emerson y Thoreau, haciendo notar un profundo desprecio, como filósofos amateurs. Stanley Cavell, uno de los filósofos norteamericanos más reconocidos en el siglo XX, se pregunta al respecto:

¿Cómo es que América no se ha expresado nunca ella misma filosóficamente? [...] Y el contexto de la pregunta implicaba que considero que la pregunta por la expresión filosófica americana va unida a la de si Thoreau (y Emerson) han de ser aceptados como filósofos (2002: 68-69).

La respuesta supone una toma de decisión. Ambos representantes de la corriente trascendentalista alcanzan un modo de hacer filosofía poco habitual para la tradición y son considerados, en ese sentido, "amenazas" al sistema. "Proponen, y encarnan", sostiene Cavell, "un modo de pensamiento, un modo de precisión conceptual, tan esmerado como cualquier otro que pueda imaginarse dentro de la filosofía establecida, pero imperceptible para esa filosofía porque se basa en una idea de rigor extraña a su sistema" (2002: 72). La diferencia fundamental radica, en primer término, en una falta de sistematización de sus principios lo cual, sin embargo, no implica en modo alguno un desprecio por las formas del saber académico o institucionalizado. En segundo lugar, reside en una dedicación, y por qué no, entrega a la lectura de la tradición continental, lo que produce como resultado un aprendizaje muy distinto del canónico que provoca una resistencia al 
momento de las clasificaciones. Martí, que ha contribuido en sus ensayos al debate sobre la cuestión (ver "Emerson" O.C. 9: 318), apoyaba el gesto emersoniano de impulso a un pensamiento autónomo.

En este punto, la discusión acerca de la existencia misma de una filosofía y de la falta de sistematización en sus obras asocian a Emerson y Martí, porque ambos pensadores manifiestan un modo diferente de incursionar en la reflexión filosófica que se distingue del tradicional, y que implica desaprender lo aprendido hasta el momento para enfatizar lo propio; es decir, conocer para luego desatender los severos preceptos que indicaban el modo en que debía pensarse una filosofía y que hicieron depender durante largo tiempo la vida intelectual americana de su modelo europeo. ${ }^{5}$ Esto podría sintetizarse, de nuevo, en una afirmación de Cavell: "la represión de Emerson y Thoreau como pensadores va unida a la de su autoridad como fundadores" (2002: 89).

Esa insistente búsqueda de una autonomía cultural ha afectado sin lugar a dudas su reputación entre los intelectuales del ámbito filosófico lo que los convierte, de algún modo, en los "raros" e impide apreciar la riqueza de su pensamiento. El pensamiento americano de Emerson, primero, y el de Martí, luego, se sustentan en la idea de generar la reflexión desde la configuración de una cartografía que podría considerarse propia y en la que domina una perspectiva americana aun cuando en ella se encuentre incluida Europa. ${ }^{6}$

En el camino de esa intensa búsqueda de una expresión cultural autónoma americana frente al predominio de la cultura europea en el siglo XIX, ante todo

${ }^{5}$ Como un modo de confirmación de esta serie de lecturas ofrecemos como ejemplo una cita de Jorge Mañach en su artículo "El pensador en Martí", publicado en la revista de avance en 1929: "Martí ciertamente no necesita que se le hagan mercedes. Ni la más acuciosa exploración de su ideario permitiría encontrar en él una gran faena de meditación sistemática. Es demasiado heterogénea, demasiado urgida y ocasional las más de las veces, para que pueda servir de cauce a un ancho caudal de pensamiento puro. [...] Pero, advertida esa limitación que un entusiasmo un poco crítico pudiera ocultarnos, no sería licito desconocer que la obra escrita de Martí evidencia una calidad de pensamiento inusitada en nuestra América por su vigor, por su consistencia, por su frecuente hondura y hasta por la originalidad con que anticipa, fugazmente, alguna de las actitudes intelectuales características de nuestro tiempo (Mañach 1995: 189-190). La crítica de Mañach reitera algunos de los lugares comunes de la crítica filosófica: por un lado, atiende a la falta de organicidad y sistematización en la obra y, por el otro, considera dificultosa y, en algún punto, extraña la posibilidad de producir un pensamiento profundo y original desde nuestro continente.

${ }^{6}$ Pese a la común voluntad de fundar un pensamiento americano, existe, no obstante, una notoria diferencia entre ambos autores: mientras que Emerson desconoce en algún punto la tradición nacional, lo que Cavell ha denominado "el deseo de fundar un pensamiento sin fundadores [...] con Padres Desconocidos” (2002: 90), Martí indaga, décadas más tarde, en el pasado americano para encontrar su lugar. 
francesa, Martí se encuentra con el discurso trascendentalista emersoniano. Así, sostiene Ballón:

Emerson, como principal iniciador del llamado "American Renaissance", representa para Martí no únicamente la posibilidad de una literatura afincada en lo propio americano, sino, además, un modo original de ver y asumir el desarrollo de la historia cultural del continente, en medio del vertiginoso proceso de cambio provocado por al advenimiento del fenómeno universal de la modernidad (1995: $13)$.

En este sentido y frente a las repetidas denegaciones de la autoridad de Emerson para intervenir en el campo del pensamiento filosófico, Martí lo distingue, engrandece a Emerson en las discusiones y lo llama "filósofo", quizás como un modo de rechazar esas improductivas acusaciones a su filosofía de amateur. Así, y por el contrario, acordamos con Ballón cuando reconoce que, con este discurso, al recuperar a Emerson a través de Martí "se inicia un nuevo modo de ver al hombre y al mundo americanos" (1995: 20).

El proyecto cultural autónomo americano que Martí halló en Emerson y que, por su parte, también asumió, lo condujo a fortalecer a fines del siglo XIX los lazos entre dos tradiciones, la cubana (y, en consecuencia, latinoamericana) y la estadounidense que, si bien contaban con una larga historia en común, no habían sido hasta el momento objeto de una reflexión que afianzara de manera concluyente esos lazos. El gesto martiano instituye, en definitiva, un vínculo entre las dos Américas.

Martí ha dedicado gran parte de su pensamiento a establecer relaciones entre el hombre y la naturaleza, es decir, entre el mundo que lo rodea y la historia, el momento en que vive. Estas relaciones se fusionan y manifiestan en el concepto de hombre natural: aquél que se encuentra en armonía con la naturaleza y atravesado por la historia, noción que Martí toma de la filosofía de Emerson. Algunas de las opiniones de Martí con respecto a la obra de Emerson aparecieron en sus crónicas, como la semblanza publicada con motivo del fallecimiento del filósofo, así como también en poemas, juicios y apuntes. A partir de allí se analizan las conexiones que le permitieron a Martí introducirse en su obra (esto es, en relación con las traducciones, los artículos en periódicos y el contacto estrecho con la poesía de Walt Whitman). Este trabajo conforma así una aproximación a la concepción filosófica de Martí y sus vínculos con la tradición norteamericana.

Martí mostró un interés muy profundo por la propuesta de autonomía cultural americana de Emerson entendida como proyecto de liberación, una preocupación que lo acompañó desde sus inicios intelectuales y que se hizo evidente en dos textos anteriores a su llegada a Nueva York y a su contacto directo con la obra de Emerson. El primero de ellos figura en la presentación de la Revista Guatemalteca y el siguiente en los "Propósitos" de la Revista Venezolana. En el Cuaderno de 
Apuntes $\mathrm{n}^{\circ} 6$ aparece una versión de la fundamentación de esta última que sintetiza la postura de Martí frente a la autonomía cultural americana:

Nacidos en una época turbulenta, arrastrados al abrir los ojos a la luz por ideas ya hechas y por corrientes ya creadas, obedeciendo a instintos y a impulsos, más que a juicios y determinaciones, los hombres de la generación actual vivimos en un desconocimiento lastimoso y casi total del problema que nos toca resolver.-A estudiarlo, establecerlo y dilucidarlo, viene este periódico. A ponernos en posesión de nosotros mismos.-A hacernos dueños de nosotros, y prepararnos de manera que no sirvamos ciegamente a sombrías intenciones o a vergonzantes intereses. A sacar a la luz lo que está en la sombra, y a luchar a la luz.Establecer el problema es necesario, con sus datos, procesos y conclusiones.Así, sinceramente y tenazmente, se llega al bienestar: no de otro modo.- $\mathrm{Y}$ se adquiere tamaños de hombres libres (O.C. 8: 56).

Este texto cobra otra dimensión puesto en relación con la conferencia de Emerson "The American Scholar", que, con amplia repercusión, Emerson ofreció en 1837 para un círculo de intelectuales, y que fue considerada desde entonces como un documento fundacional, algo así como una declaración explícita de autonomía cultural del individuo y del pueblo norteamericano. ${ }^{8}$ Proponía, además, la posibilidad de un desarrollo autónomo de la cultura americana que marcó el comienzo de la emancipación espiritual y cultural del pensamiento y la literatura

${ }^{7}$ El término scholar ha ido traducido de modos diferentes en las traducciones de la obra de Emerson. Parece apropiada, no obstante, la nota aclaratoria de Antonio Lastra y Javier Alcoriza, recientes traductores de algunos de sus libros para aproximarse a una definición más abarcativa del término. "La traducción de scholar ofrece dificultades si queremos conservar el sentido que Emerson le dio en "The American Scholar" y en innumerables pasajes de sus obras. En esencia, el escolar es el propio Emerson, por lo que el concepto puede interpretarse con una perspectiva autobiográfica, pero también identifica una función social. Se trata de un tipo de hombre representativo -como el trascendentalista, el joven americano, el reformador, el poeta o el conservador, por mencionar algunos de los significados que Emerson le dio- dotado de todas las cualidades de la experiencia que la escritura trataba de renovar. Desde luego, traducir "scholar" por "sabio", "intelectual" u "hombre de letras" sería erróneo y "erudito", "investigador", "filólogo" e incluso "filósofo" carecerían de la cercanía a la vida indispensable para Emerson" (Alcoriza y Lastra 2004: 12).

${ }^{8}$ Debido a la amplia difusión de esta conferencia, la influencia de Emerson en el campo cultural estadounidense se incrementó de manera notable y excedió a partir de ese momento los límites del campo universitario en que se desarrollaba: "Una posición que le permitiría ya a la altura de los años cuarenta ser el faro guía tanto intelectual como espiritual, aspectos muy relacionados en el sentir de la época y del sitio" (Jiménez Arribas 2009: 20). En ese pensamiento se destaca el perfil de un pensador independiente que expresa, al mismo tiempo, un verdadero compromiso ético con el mundo que lo rodea. 
norteamericanas, aspecto al que Martí prestará gran atención. La preocupación emersoniana por la fundación de un pensamiento autónomo ha constituido indudablemente el centro del interés martiano en su obra. En ella aseguraba: "Nuestro día de dependencia, nuestro largo aprendizaje en la sabiduría de otras latitudes se acerca a su final. ¿Quién puede poner en duda que la poesía renacerá y traerá una nueva era? (Emerson 2009: 115-116). Como plantea Rama: "Es la segunda vez en la historia cultural de Hispanoamérica -la primera correspondió a la generación romántica del Salón Literario porteño- que se plantea tan drásticamente el enfrentamiento de los jóvenes con las ideas y sistemas imperantes de los mayores" (2015c: 30).

En consecuencia, y a partir de la reflexión de Arcadio Díaz Quiñones (2006) acerca de la importancia de establecer en la instauración de una escritura, los comienzos de la formación de un intelectual, nos hemos propuesto reconsiderar el lugar que ocupa Martí en la tradición literaria e intelectual nacional y su posicionamiento respecto de otras tradiciones. (Pampín 2015a y Pampín 2015b). Así, planteamos recolocar a Martí en un entre-lugar (Santiago 2000), un concepto que posibilitó reconocer una intensa relación entre, al menos, dos tradiciones: la cubana y la norteamericana que, pese a estar muy vinculadas entre sí a lo largo del siglo XIX, no ha sido aún explicitada lo suficiente. Este concepto, que funciona como una metáfora, nos ha permitido generar ese tercer lugar en el que se inscribe la literatura martiana, superando así las lecturas de la dependencia de las literaturas centrales y volviendo productivo el resultado. Ello permitió, al mismo tiempo, evidenciar una serie de reflexiones en torno a la autonomía cultural del continente americano tanto en Emerson como en Martí y sostener un diálogo equilibrado a nivel intelectual entre ambas producciones. En última instancia, implica recolocar la obra de Martí en el centro del canon occidental, equiparando la literatura martiana con figuras preponderantes de la modernidad decimonónica, contemporáneas de Martí, como Emerson o Whitman. En este sentido, esta nueva perspectiva amplía la lectura de Martí, tradicionalmente limitada al marco de la tradición caribeña y latinoamericana.

Así, la interpelación de un conjunto de textos del período neoyorquino (18811995), con énfasis en los ensayos "Emerson" y "El poeta Walt Whitman" y en las traducciones de autores vinculados al círculo trascendentalista, permite considerar el modo en que el discurso norteamericano se resignifica en el corpus martiano.

\section{El eje Emerson-Whitman-Martí}

La obra de Martí incluye innumerables referencias a la obra de Emerson. Las más destacadas son dos colaboraciones publicadas en periódicos, dos notas de sus cuadernos de apuntes, una de ellas evidentemente incompleta, la traducción del poema "Fable" (en la versión martiana, "Cada uno a su oficio") y algunos borradores de traducciones de poemas que no llegó a publicar. 
En ese conjunto, el texto más importante es la crónica que escribe el 6 de mayo con motivo del fallecimiento del filósofo y poeta, acontecido el 27 de abril de 1882, una noticia muy difundida en la prensa norteamericana. La nota fue publicada en $\mathrm{La}$ Opinión Nacional, de Caracas, periódico en el que Martí fue un asiduo colaborador, el 19 de mayo siguiente y puede leerse como un homenaje en el que realiza un exhaustivo recorrido por su obra literaria y filosófica con una perspectiva que, si bien se presenta como crítica, podría ser considerada al mismo tiempo como íntima o personal. A partir de ese momento y en adelante, la amplísima difusión de este artículo dio a conocer a Emerson en la América hispana.

Martí traduce en la semblanza en forma literal o libre, parafrasea, amplifica, suprime, glosa, sustituye partes de fragmentos de ensayos. En su texto se encuentran referencias a los ensayos "Self-reliance" ("Confianza en uno mismo"), "Friendship" ("Amistad"), "Spiritual Laws" ("Leyes espirituales"), "Circles" ("Círculos"), "Art", incluidos en First Series. Del siguiente volumen, Second Series, cita "The poet" (El poeta), "The Over-Soul" ("El Alma Universal" o "La Supra Alma"), y "Nature" ("Naturaleza"). También refiere a conferencias como "The American Scholar", "Poetry and Imagination" ("Poesía e imaginación") y volúmenes completos como Letters and Social Aims (Cartas y objetivos sociales), Society and Solitude (Sociedad y Soledad), Conduct of Life (La conducta de la vida), English Traits (Rasgos ingleses), Representative Men y, por supuesto, Nature. La recuperación de estas referencias, en su mayoría implícitas, ${ }^{9}$ permite demostrar que tan solo un año después de su llegada a Nueva York Martí había no solo leído sino, lo que es más importante, aprehendido profundamente la obra emersoniana.

Una gran cantidad de las reflexiones que aparecen en la crónica martiana le son sugeridas por la sutil y honda lectura de Nature. Puede afirmarse que esta crónica se sostiene en la filosofía de la naturaleza de Emerson tal como había sido explicitada en ese libro que Martí recorre de manera exhaustiva para sintetizar los conceptos fundamentales que permiten comprender esa teoría.

En su presentación, Martí define a Emerson como un hombre grandioso y para hacerlo utiliza la propia definición del filósofo que se desprende de Representative Men. Según Martí, Emerson, del mismo modo que esos hombres, posee la capacidad de ver más allá que el resto de la sociedad, es por eso que considera necesario rescatar sus visiones de la naturaleza:

${ }^{9}$ Remitimos a la crítica de Fountain (2003a y 2003b), Ballón (1986 y 1985) y Mary Cruz (1982, 1984, 1988 y 1995-1996), que han realizado ya exhaustivos estudios sobre el tema. Estos autores realizan un profundo trabajo comparatista, especialmente, entre las obras de Emerson y de Whitman con la de Martí para hallar puntos de contacto en los textos e indicar los recursos utilizados por Martí en sus traducciones. 


\begin{abstract}
¿Qué quién fue ese que ha muerto? Pues lo sabe toda la tierra. Fue un hombre que se halló vivo, se sacudió de los hombros todos los mantos y de los ojos todas esas vendas, que los tiempos pasados echan sobre los hombres, y vivió faz a faz con la naturaleza, como si toda la tierra fuese su hogar; y el sol su propio sol, y él patriarca. Fue uno de aquellos a quienes la naturaleza se revela, y se abre, y se extiende los múltiples brazos, como para cubrir con ellos el cuerpo todo de su hijo. Fue de aquellos a quienes es dada la ciencia suma, la calma suma, el goce sumo (O.C. 9: 311-312).
\end{abstract}

La semblanza de Emerson enumera algunas de las características de los grandes hombres, que deben ser, desde luego, los hombres naturales, aquellos que tienen, entre otros rasgos, sabiduría para comprender la naturaleza, unidad con los elementos naturales y una distintiva capacidad para ver. Martí compara el propio retrato de Emerson con la naturaleza: la frente es como la ladera de una montaña y su nariz se asemeja a la de los pájaros. Martí presenta a Emerson como un sacerdote de la naturaleza, que es su templo: "para él no hay cirios como los astros, ni altares como los montes, ni predicadores como las noches palpitantes y profundas" (O.C. 9: 325).

Se destaca, al mismo tiempo, en el ensayo, la exposición del método de pensamiento de Emerson:

A veces, parece que salta de una cosa a otra, y no se halla a primera vista la relación entre dos ideas inmediatas. Y es que para él es paso natural lo que para otros es salto. Va de cumbre en cumbre, como gigante, y no por las veredas y caminillos por donde andan, cargados de alforjas los peatones comunes [...]. Sus libros son sumas, no demostraciones. Sus pensamientos parecen aislados, y es que ve mucho de una sola vez, y quiere de una vez decirlo todo, y lo dice como lo ve... (O.C. 9: 323).

Su método se simplifica en la asociación libre de ideas y en la mirada abarcativa, nunca detallista: ver mucho de una sola vez -el hombre y la naturaleza- y querer decirlo todo. Martí revela la capacidad visionaria del filósofo que se mantiene como una constante en el ensayo: "iQué visiones, las de sus ojos!” (O.C. 9: 312-312). Y más adelante añade, “¿Cómo había de ser culpa suya que los demás no poseyesen aquella luz esclarecedora de sus ojos?" (317) y luego: "El veía detrás de sí al Espíritu Creador que a través de él hablaba a la naturaleza. Él se veía como pupila transparente, que lo veía todo, y sólo era pupila" (317). El tópico del poeta visionario, de indiscutible herencia romántica, constituye un modo de conocimiento del Universo y de aproximación a la naturaleza. Así, comprendida la visión como una vía de acceso a la realidad que no requiere mediatizaciones, supone una relación más estrecha entre el poeta y la naturaleza. Esta capacidad visionaria distingue al poeta del resto de los hombres. La manera de expresar esa visión tan particular de la naturaleza y el espíritu es mediante el proceso creativo, a través de 
la poesía (la figura del poeta visionario será retomada por Martí en los prólogos a Ismaelillo y a Versos libres). Es una virtud que se revela en la niñez y que, por fortuna, algunos adultos logran conservar: " ¡Sus versos, qué vuelos de ángel!” (313) exclama Martí. La imagen del niño recorre el ensayo y emparenta a Emerson con el niño protagonista del Ismaelillo. La figura del poeta como ser alado también es recurrente en el ensayo: "Se siente como perder de alas. Se vive como a la luz de una estrella" (310), dice unos momentos antes.

El ensayo va revelando una a una las verdades que sostienen al trascendentalismo de Emerson:

Él no ve más que analogías: él no halla contradicciones en la naturaleza: él ve que todo en ella es símbolo del hombre, y todo lo que hay en el hombre lo hay en ella. Él ve que la naturaleza influye en el hombre, y que este hace a la naturaleza alegre, o triste, o elocuente, o muda, o ausente, o presente, a su capricho. Ve la idea humana señora de la materia universal. Ve que la hermosura física vigoriza y dispone el espíritu del hombre a la hermosura moral (327).

Una sola cita condensa varios de los ejes conceptuales de Nature. Así Martí entiende, primero, que Emerson no solo ve a través de visiones sino que estas producen analogías. Y que, en consecuencia, las leyes físicas se corresponden con las leyes morales: existe una moral de la naturaleza. Por último, lo uno va a dar en lo múltiple, el yo en el no-yo, el hombre en el universo. Porque, en definitiva, todos los seres de la naturaleza son semejantes e iguales en su composición, aunque el hombre sobresale entre todos ellos y la domina.

Pese a esa gran capacidad de adquirir saberes que posee el poeta, Martí entiende que Emerson establece prioridades en el momento de conocer. Escribe Martí: "Lo que enseña la naturaleza le parece preferible a lo que le enseña el hombre. Para él un árbol sabe más que un libro; y una estrella enseña más que una universidad" (325). El mundo natural resulta más valorado que el mundo intelectual, un asunto que Martí retomará en "Nuestra América". Como señala Rojas, "tal vez, lo que más atrajo a Martí de los trascendentalistas es la combinación de ese naturalismo con un sentido práctico de la cultura" (2000: 61) ya que sus propuestas educativas y morales se apoyaban en el conocimiento basado en una aproximación a la naturaleza que permitiera moldear la personalidad del hombre.

Emerson, en representación del hombre natural, vive en comunión con la naturaleza, en una unión pura y trascendente: "Toda la naturaleza palpitaba en él, como una desposada" (312). Esta imagen de goce en la naturaleza en la que el hombre se une a ella como un enamorado, aparecerá también en la poesía de Whitman y será una cuestión capital en los Diarios martianos.

Finalmente, y no por eso en menor medida, Martí enfatiza la autonomía reflexiva a la que aspira Emerson, siempre fiel a sí mismo: "Jamás se vio hombre alguno más libre de la presión de los hombres y de la de su época. Ni el porvenir le 
hizo temblar ni le cejó el pasado" (318). De inmediato, afirma que Emerson: "No obedeció a ningún sistema, lo que le parecía acto de ciego y de siervo, ni creó ninguno, lo que le parecía acto de mente flaca, baja y envidiosa" (O.C. 9: 318-319). Se trata de una lectura profunda de "The American Scholar": un intelectual que posee confianza en sí mismo y traza un recorrido propio.

En la crónica de la muerte aparece también la imagen del artista propuesta por Emerson en sus ensayos (Nature, "The American Scholar" y "The Poet") y se confunde, ¿involuntariamente?, con la escritura martiana. La identificación de Martí con Emerson no permite, en múltiples oportunidades, diferenciar a quién pertenece cada tramo de la escritura. Esta característica constituye un lugar común de la crítica que aborda la relación entre ambos autores, desde el temprano ensayo de Félix Lizaso (1954) hasta las lecturas de Fountain (2003b) y de Ballón (1986).

El 23 de mayo de 1882, cuatro días después de la publicación del ensayo, Martí entrega en la "Sección constante" del mismo periódico una nueva colaboración, muy breve, dividida en dos partes bien diferenciadas (O.C. 23 1991: 305-306). En la primera parte reseña una novedad bibliográfica rusa y en la segunda, que no lleva título, regresa con insistencia a la noticia del fallecimiento de Emerson para reforzar la imagen de la figura más notable del trascendentalismo. Esta noticia, a diferencia del texto publicado el 19 de mayo, está dirigida a un público más general y no al específico lector literario (por la sección en la que se incluye), y pese a ello, reitera algunas ideas fundamentales del primer ensayo. En breves líneas sintetiza algunos de sus libros, entre los que destaca Naturaleza y Hombres representativos, volúmenes que había traducido con insistencia en el artículo del 19 de mayo. Este artículo, al igual que el anterior, no sólo se presenta como una confirmación de las lecturas que Martí realizó de la obra de Emerson sino que da cuenta, además, de una presencia constante en su escritura. Ambas piezas, como señala Mary Cruz, "no obstante ser tan disímiles en propósito, apariencia y efecto, guardan relación temática y estructural" (1982: 80). ${ }^{10}$

Luego se hallan dos escritos que permanecieron inéditos hasta la edición de las Obras Completas. En un artículo mecanografiado de cuatro páginas, titulado "Emerson" (O.C. 19 1991: 353-356), sin fechar, aunque se presume posterior a la necrológica, se ocupa en particular de dos temas centrales que ponen de manifiesto la identificación de Martí con las ideas emersonianas: la lógica del poeta norteamericano y la creación mediante la escritura que deriva de ella, que retoma de su ensayo.

${ }^{10}$ Finalmente, Martí publicó un tercer artículo en El Partido Liberal el 5 de febrero de 1890, que mucho tiempo después será incluido en la Edición Crítica de las Obras Completas en el año correspondiente. 
En el inicio del artículo reitera las ideas desarrolladas en su crónica acerca de los procedimientos utilizados por Emerson al momento de reflexionar. Allí, además, añade una explicación sobre la producción de las "visiones" como una vía epistemológica. "Las ideas no se presentaban a Emerson en ramazón, ni en quietud lineal, ni en su dependencia menuda y ordinaria: las veía a trozos, cual suele en días oscuros aparecer el sol entre las nubes. Tenía siempre los ojos abiertos, acaparando analogías" (O.C. 19 1991: 353). A estos poetas con capacidad especial para ver, entre los que se incluyó Martí, los denominó hipéricos, por contraposición a los miopes, que solo pueden ver fragmentos de realidad.

A partir de allí, el resto del escrito se manifiesta como un ejercicio de reflexión. Son frases sueltas que se ocupan de temas aislados y que no revelan una unidad en el análisis.

El último texto relevante de Martí sobre Emerson es otro estudio, por cierto incompleto, que se inicia a máquina y continúa en manuscrito (O.C. 22 1991: 15658), aún más breve, donde reitera las mismas reflexiones en torno a la producción intelectual de Emerson con algún insignificante cambio en el vocabulario. Innumerables referencias se diseminan por toda la obra, algunas veces explícitas acerca de quien llamó el primer poeta de América y otras implícitas, en alusión a su filosofía de la naturaleza.

Con el propósito de rastrear los diferentes modos en que la obra de Emerson ingresa en los textos de Martí se vuelve necesario interpelar otros escritos del período neoyorquino, por ejemplo, sus traducciones, una selección de la moderna literatura norteamericana: Emerson, Poe, Motley, Longfellow y Whitman quienes fueron, en algún momento, fundadores, miembros o epígonos del movimiento trascendentalista.

La predilección de Martí por la literatura norteamericana se asocia a la aceptación de una filosofía basada en el conocimiento de la naturaleza y a la de una actitud que propicia la autonomía política y cultural. En eso está pensando precisamente Martí cuando lee la tradición norteamericana.

Siempre en relación con Emerson, aparte de los fragmentos que traduce e incorpora en los ensayos o que copia en sus apuntes, se destacan algunos poemas que se asocian a la idea de naturaleza de Emerson que Martí resignifica. Su elección, por tanto, no es fortuita.

"Emerson" con el nombre del autor como título es una traducción de "The World Soul" ("El alma del mundo"). Se trata de un poema extenso en el que la fuerza de la naturaleza, siempre recargada de gozo, enfrenta a la oscura ciudad moderna: "Naturaleza, que lo ama todo, / También sonríe en las oscuras fábricas" (O.C. 21: 458). Sus hoteles, fábricas, comercios o calles multitudinarias, símbolos de esa modernidad incipiente, se acompañan persistentemente de connotaciones negativas: "Tranvías, calles y comercios enredan, / Flojos nuestros cuerpos andan / Urdimos, corrompémonos, y al mismo niño / Aún no nacido su heredad se arranca (O.C. 21: 457). La ciudad es el espacio que engendra el vicio y la corrupción; la política es 
"villana" y la literatura no logra reconfortar al hombre. Sin embargo, y como contraposición a esa cruenta imagen de la cultura, a pesar de ello, la naturaleza siempre renace. "Brillar el verano miro / sobre las cumbres nevadas, / Y a través de la gélida ventisca / ¡Los rosales calientes se levantan!” (O.C. 21: 460). Estos dos últimos versos expresan en el cierre del poema que la naturaleza es la última esperanza para el hombre.

Otro poema, sin título, que se identifica con el primer verso del poema "Adiós, mundo proud, me vuelvo a casa" 11 es la traducción de "Good-bye, proud world" de Emerson. Las notas que acompañan la edición de las Obras Completas de Martí atribuyen los espacios en blanco y las palabras inteligibles en el original a las dificultades de Martí en el momento de traducir. A pesar de esto en la lectura se alcanza a percibir la angustia que aqueja al sujeto poético preguntándose por el destino de la humanidad. Se reitera la imagen de la multitud que irrumpe en las ciudades ("Mucho he vagado entre tus turbas tristes") y las desdichas que la vida en ellas acarrea: "Adiós al rostro vil de la Lisonja / A la sabia de la grandeza, ${ }^{12}$ / Al ojo espurio del Dinero erguido: / Al puesto plegadizo, al alto y al bajo; / A los pasillos llenos, y a las calles, / A los rápidos pies y almas heladas, / Adiós a los que van y a los que vienen / Adiós, mundo, me vuelvo a casa (O.C. 21: 461). La velocidad del hombre en las ciudades ("los rápidos pies"), el cerco de vicios, lo corrupto, despierta miradas negativas en el poeta que solo puede percibir la frialdad cubriendo el alma humana ("almas heladas"). Por eso, se puede leer: "Vuelvo al hogar de piedra todo mío / Allá entre aquellos cerros solitarios, / Refugio silencioso en tierra bella"; la decisión final implica el abandono del mundo y el retiro a la naturaleza, como hogar antiguo del hombre. El abandono de la ciudad hacia zonas apartadas es un tópico utilizado con insistencia en la poesía del romanticismo inglés.

Por desgracia, Martí no finalizó estas traducciones como para poder ser publicadas, no obstante, resulta muy útil acceder a esos apuntes aun sabiendo que se encuentran inconclusos en la medida que revelan las lecturas y el interés de Martí en los poemas de Emerson y permiten, al mismo tiempo, comprender los mecanismos de traducción. Por otra parte, Martí tradujo, en una versión libre, muy elaborada, el poema "Fable", publicado bajo el título "Cada uno a su oficio" en la revista infantil La Edad de Oro que fue considerado en una oportunidad anterior (Pampín 2014).

Martí traduce además dos poemas de Henry Longfellow que tampoco finaliza. ${ }^{13}$ Además, tradujo un fragmento de "Annabel Lee" de Edgar Allan Poe y de "Lalla

${ }^{11}$ En inglés en el manuscrito original. Puede traducirse como orgulloso, soberbio, altivo.

${ }^{12}$ En blanco en el original.

${ }^{13}$ Los espacios en blanco así como una gran cantidad de tachaduras y palabras escritas al margen de los manuscritos enfatizan las dificultades al momento de traducir. Al primero lo 
Rookh" de Thomas Moore. También leyó con avidez la obra de Longfellow y escribió dos valiosos ensayos en los que además de revalorizar el rol del traductor declara un abierto interés por la obra de uno de los fundadores de la literatura norteamericana. Esos textos fueron publicados en La Opinión Nacional el 22 de marzo y el 11 de abril de 1882 a la muerte del entonces ya consagrado poeta nacional; en el mismo diario que los ensayos sobre Emerson y tan solo unas semanas antes. Es decir que en el transcurso de un mes y medio Martí publica los cuatro textos dedicados a las que en ese momento podían considerarse las dos figuras más importantes de la literatura norteamericana.

Unos meses más tarde, en una carta a Bartolomé Mitre Vedia del 19 de diciembre del mismo año escribirá:

Cuando hablo de literatura, no hablo de alardear de imaginación, ni de literatura mía, sino de dar cuenta fiel de los productos de la ajena. Aunque ya han muerto Emerson y Longfellow, y Whittier y Holmes están por morir. De prosistas hay muchedumbre, pero ninguno hereda a Motley. Hay un joven novelista que se afrancesa, Henry James. Pero queda un grandísimo poeta rebelde, y pujante, Walt Whitman, y apunta un crítico bueno, Clarence Stedman (O.C. 17: 355).

Con el fallecimiento de sus fundadores, la literatura norteamericana quedaba huérfana $\mathrm{y}$, frente a ese desamparo $\mathrm{y}$ al temor de una nueva intromisión de la literatura francesa, que ya percibe en Henry James, Martí eleva de forma inmediata a Walt Whitman, el poeta nuevo, que por su rebeldía no ocupa todavía un lugar en la tradición norteamericana. Pasarán largos años para que el poeta de la democracia pueda ganar ese espacio. Mientras tanto, en ese transcurrir, Martí escribe uno de sus más importantes ensayos: "El poeta Walt Whitman", publicado en El Partido Liberal de México el 17 de mayo de $1887 .{ }^{14}$

titula "De Longfellow" y es la versión del poema "It is not always May". Representa la imagen de una naturaleza encendida, vigorosa, fecunda: "El aire es puro, brilla el Sol, el canto / Alza la golondrina vocinglera". Y luego continúa: "Todo es nuevo: en las nobles ramas viejas / nueva es la flor, las hojas, el rocío" (Martí O.C. 21: 463).

El siguiente poema es una traducción de los primeros versos de "The Song of Hiawatha" (1855), basado en la mitología de los nativos de Norteamérica. Ocasionalmente completos cuando Longfellow menciona los nombres de tribus nativas, sus cinco párrafos sirven de marco para ingresar al relato. Es una naturaleza que es mucho más que un escenario: es productora de relatos: "Preguntáisme, y estos cuentos, / Estas viejas tradiciones,

Con olores de foresta, / Con el fresco de los llanos, / Con el humo de las chozas, / Con el ruido de hondos ríos, / Con palabras repetidas, / Con salvaje centelleo / Como el trueno en las montañas" (O.C. 21: 465).

${ }^{14}$ Inmediatamente después de publicado el ensayo La Nación de Buenos Aires del 26 de mayo del mismo año inserta una crónica que se ocupa del mismo tema: "Un poeta. Walt 
Martí se interesa en Whitman en la medida que vuelve explícita la unión y el goce de los elementos de la naturaleza en su relación con el espíritu y el cuerpo humano teorizados por Emerson.

La armonía y el equilibrio de los elementos de la naturaleza que Emerson percibía en el Universo se manifiestan a través de la voz del hombre nuevo, que vive en un estado de permanente goce corporal y espiritual. Algunos fragmentos de Song of Myself (Canto de mí mismo) expresan esta profunda relación de cuerpo y alma que el sujeto poético de Whitman mantiene con la naturaleza:

Soy el poeta del Cuerpo y soy el poeta del Alma

[...]

Yo soy el que camina con la tierna y creciente noche,

Llamo a la tierra y al mar que abraza la noche.

Abrázame, noche de senos desnudos, abrázame, noche magnética y fecunda

Noche de los vientos del sur, noche de las estrellas grandes y escasas

Noche serena que me llama, loca y desnuda noche de estío.

¡Sonríe, tierra voluptuosa de fresco aliento!

Tierra de los árboles dormidos y húmedos,

Tierra del sol que ya se ha ido, tierra de las montañas de cumbre nebulosa,

Tierra del cristalino fluir de la luna llena, apenas tocada de azul

Tierra del brillo y de la sombra manchando la corriente del río

Tierra del gris límpido de las nubes que resplandecen y se aclaran para que yo las vea,

Tierra yacente y extendida, rica tierra de azahares!

Sonríe, pues llega tu amante.

Pródiga me has dado tu amor, te doy pues mi amor mi apasionado amor indecible (1997: 71).

Ese goce del cuerpo se advierte, por ejemplo, en el poema siguiente al que se declaraba amante de la naturaleza ("Sonríe, pues llega tu amante", decía). Aquí, Whitman ofrece una sensual imagen del mar, que rebasa sus formas hasta el erotismo, hasta volverse uno con el cuerpo del hombre:

¡Mar!, a ti me abandono también, adivino lo que quieres decirme,

Miro desde la playa observo tus encorvados dedos que me invitan,

Creo que no quieres volver sin haberme tocado,

Salgamos juntos de paseo, me desnudo, perdamos de vista la tierra,

Whitman". Se trata del mismo texto con diferencias marcadas en la organización de los párrafos. 
Acúname con suavidad, méceme en tu sueño ondulante,

Salpícame de amorosa humedad, yo puedo retribuirte.

Mar henchido te embraveces,

Mar que respiras, hondo y revuelto,

Mar en que está la sal de la vida y mar de cerradas sepulturas aun no cavadas,

Rugiente mar que engendras tempestades, mar delicado y, caprichoso,

Soy universal como tú, soy también de una faz y de muchas fases (1997: 73).

El vínculo que la filosofía de Emerson proponía entre todos los seres del universo y la naturaleza se revelan así en la poesía whitmaniana en la que Martí encuentra el sistema analógico que se sustenta en el discurso trascendentalista emersoniano tal como lo expresa en su ensayo:

El mundo, para Walt Whitman, fue siempre como es hoy. Basta con que una cosa sea para que haya debido ser, y cuando ya no deba ser, no será. Lo que ya no es, lo que no se ve, se prueba por lo que es y se está viendo, porque todo está en todo, y lo uno explica lo otro, y cuando lo que es ahora no sea, se probará a su vez por lo que está siendo entonces (O.C. 13: 136).

Este fragmento martiano explicita cabalmente la idea de Whitman en el Poema 3 de Canto de mí mismo:

Dulce y límpida mi alma, límpido y dulce todo lo que no es mi alma.

Si falta uno de los dos, los dos faltan, y lo invisible se prueba por lo visible, se ve lo que se ve lo prueba.

Hasta que este se haga invisible y requiera prueba a su vez (Whitman 1997: 27).

No obstante, no es la primera vez que Martí refiere al sistema analógico de leyes perfectas que sostiene la relación entre el hombre y la naturaleza. En 1875, a raíz de las inundaciones producidas en Francia, anotaba en su cuaderno de apuntes: "Todo es análogo en la tierra, y cada orden existente tiene relación con otro orden. La armonía fue la ley del nacimiento y será perpetuamente la bella y lógica ley de relación" (O.C. 3: 39).

Como asegura Félix Ernesto Chávez, Whitman "asocia los elementos como enunciación de una teoría armónica universal, y para ello no descarta utilizar lo contradictorio como procedimiento discursivo" (2001: 163). Martí lo entiende a su modo:

Su método ha de ser grande, puesto que su efecto lo es; pero pudiera parecer que procede sin método alguno, sobre todo en el uso de las palabras, que mezcla con nunca visto atrevimiento, poniendo las augustas y casi divinas al lado de las que pasan por menos apropiadas y decentes (O.C. 25: 276). 
En los poemas de Whitman se emplean los principios espiritualistas de Emerson en tanto desaparecen antiguas dicotomías como lo próximo y lo lejano, lo bello y lo feo, lo alto y lo bajo, lo honesto y lo vil y, así también, la vida y la muerte. Las diferencias fundamentales se eliminan en favor de una armonía universal. El orden que rige el libro es el de la naturaleza. En este sentido, la poética que gobierna y sostiene Leaves of Grass (Hojas de hierba) indica que "todas las cosas son iguales porque la más ínfima contiene el universo" (Rancière 2013: 91). Esa observación, trasladada a los versos de Whitman, podría leerse del siguiente modo: "Yo creo que una hoja de hierba no es menos que el camino recorrido por las estrellas" (Whitman 1997: 131).

En esa supresión de diferencias se sintetiza también de algún modo la elección del poeta: el poema en prosa whitmaniano que vacila entre ambas tradiciones: ni en un lugar ni en el otro, el verso libre, que tal como Martí lee en Whitman y realiza en su escritura, inventa una puntuación inédita, crea neologismos y rompe los versos. ${ }^{15}$ En una temprana nota publicada el 15 de noviembre de 1881 en la "Sección Constante" de La Opinión Nacional, muy anterior al extenso ensayo de 1887, Martí refiere a:

Un poeta de los Estados Unidos, famoso por el atrevimiento de sus rimas, la osadía de sus pensamientos y el desembarazo-que raya a veces en descompostura-de su forma, está preparando y vigilando en la universitaria ciudad de Boston, en la culta y pretenciosa Boston, una colección de sus obras: el poeta es W. (O. C. 12:41). ${ }^{16}$

Es el lugar de la excepción, la anomalía del verso, aquello que marcará la escritura de la vida moderna ya que, para Martí tanto como para Whitman, el verso tradicional no resulta suficiente para dar cuenta de la experiencia de la modernidad. Esa ruptura, que en tiempos de Whitman los norteamericanos llamaron trascendentalista, en América Latina fue denominada modernismo.

Para Martí, la nueva poesía de Leaves of Grass proyecta a su autor como el gran poeta de una nueva época, la modernidad, y lo instituye en un testigo original y al mismo tiempo extraño (para Darío será todavía un "raro") del surgimiento de esa también nueva gran nación, los Estados Unidos, de sus instituciones, sus hombres, sus códigos morales y sus discursos filosóficos. Martí obtiene de Whitman la dosis

${ }^{15}$ Santí estudia la presencia de Whitman en los escritores modernistas. Sostiene que ellos lo invocan y que, en este sentido, "es un tema en su obra, no un modelo estilístico o retórico" (54). Sin embargo, como puede verse, el caso de Martí es diferente en su relación con la obra de Whitman respecto de otros autores, como Darío.

${ }^{16}$ El manuscrito que se conserva en el CEM incluye el nombre completo del autor: Whitman. 
justa de modernización formal e idealización democrática propuesta por la nueva literatura norteamericana y esto le resulta suficiente para desatender las frecuentes acusaciones en contra del poeta, no solo de índole literaria sino también las de índole moral (Rama 2015b: 209). Martí encuentra ese profundo interés en el ideal democrático en su poesía y también en las reflexiones del volumen Democratic Vistas, en el que Whitman no solo se ocupa del nuevo rol que debe jugar el poeta en la sociedad moderna sino de autoreivindicarse como el gran autor de la era democrática. Fernando Alegría considera que, gracias a su espíritu romántico, su pasión por la libertad y su ideario político, "Martí es el receptor ideal del discurso whitmaniano" (1954: 23). ${ }^{17}$

Leaves of Grass no solo representa para Martí el "libro natural" que se distancia de la sabiduría de las academias (simbolizadas en "universidades y latines"); el compromiso con su obra y su figura, lo mismo que con Emerson, se apoya también en la posibilidad de elaboración de un pensamiento autónomo:

Las escuelas filosóficas, religiosas o literarias, encogullan a los hombres, como al lacayo la librea: los hombres se dejan marcar, como los caballos y los toros, y van por el mundo ostentando su hierro: de modo que cuando se ven delante del hombre desnudo, virginal, amoroso, sincero, potente,- - del hombre que camina, que ama, que pelea, que rema,- - del hombre que, sin dejarse cegar por la desdicha, lee la promesa de final ventura en el equilibrio y la gracia del mundo; cuando se ven frente al hombre padre, nervudo y angélico de Walt Whitman, huyen como de su propia conciencia, y se resisten a reconocer en esa humanidad fragante y superior el tipo verdadero de su especie, descolorida, encasacada, amuñecada (O.C. 25: 247).

Si Whitman puede escribir Leaves of Grass, en definitiva es porque encarna al hombre natural. Aunque dedica sus cantos a Manhattan, no vive en la ciudad, y lo aclara Martí: "vive en el campo, donde el hombre natural labra el sol que lo curte, junto a sus caballos plácidos, la tierra libre" (O.C. 25: 250). Pero, de inmediato añade: "Ayer vino Whitman del campo para recitar ante un concurso de leales amigos, su oración sobre aquel otro hombre natural, aquella alma grande y dulce,

${ }^{17}$ En sentido contrario, Francisco Morán (2014) se ha propuesto discutir, en los últimos años, a partir de sus escritos periodísticos del período mexicano y luego neoyorquino, las clásicas lecturas que sostienen la perspectiva democrática martiana. En esta línea, no solo lee un Martí antidemocrático sino también racista y misógino. De igual modo, la visión tradicional que reconocía en Whitman al poeta de la democracia ha sido puesta en tela de juicio por diversos críticos norteamericanos desde hace algunas décadas. David Simpson (2010) sintetiza estas discusiones en su artículo. 
'aquella poderosa estrella muerta del Oeste', aquel Abraham Lincoln" (O.C. 25: 250, el subrayado es nuestro). ${ }^{18}$

El poeta representa, además, la correspondencia entre el sentir democrático y la literatura diversa, enfatiza, de la tradición europea:.

Los criados a leche latina, académica o francesa, no podrían acaso entender aquella gracia heroica. La vida libre y decorosa del hombre en un continente nuevo ha creado una filosofía libres y trabajadores que vio jamás la tierra, corresponde una poesía de conjunto y de fe, tranquilizadora y solemne, que se levanta, como el sol del mar, incendiando las nubes, bordeando de fuego las crestas de las olas, despertando en las selvas de la orilla las flores fatigadas y los nidos (O.C. 25: 250).

A un pueblo joven y pujante le corresponde también una literatura vigorosa, libre de antiguas y vetustas ataduras. Y "una filosofía sana y robusta", añade Martí, porque entiende que en la poesía de Whitman se explicita un pensamiento poético que se sostiene sobre una filosofía firme y convincente. Es por eso que cita textualmente una gran cantidad de versos de Leaves of Grass, en especial de "Song of Myself". Su selección evidencia que la verdad se encuentra en el goce de la naturaleza, de allí que sostenga que el poeta "se siente poseído de amor universal y frenético" (O.C. 25: 254), para luego añadir: "Sea universal el goce. Yo canto la eternidad de la existencia, la dicha de nuestra vida, y la hermosura implacable del Universo".

El lenguaje y el ritmo poético de Whitman, que se distinguen por completo de la tradición europea ("los criados a leche latina"), corresponden a la humanidad de un nuevo y brioso continente:

No de rimillas se trata, y dolores de alcoba, sino del nacimiento de una era, del alba de la religión definitiva, y de la renovación del hombre: trátase de una fe que ha de sustituir a la que ha muerto, y surge con un claror radioso de la arrogante paz del hombre redimido: trátase de escribir los libros sagrados de un pueblo que reúne, al caer del mundo antiguo, todas las fuerzas vírgenes de la libertad a las ubres y pompas ciclópeas de la salvaje naturaleza: trátase de reflejar en palabras el ruido de las muchedumbres que se asientan, de las ciudades que trabajan, de los mares y los ríos esclavos (O.C. 25: 259).

Esa nueva fe que manifiesta Whitman encuentra su base en el trascendentalismo de Emerson: "cree que la religión perfecta está en la naturaleza (O.C. 25: 269). Por

${ }^{18}$ Martí escribe la crónica motivado por la visita de Whitman a la ciudad. El texto de Martí está fechado el 19 de abril de 1887. Cinco días antes Whitman había ofrecido una conferencia en el Madison Square Theatre de Nueva York con motivo del aniversario del fallecimiento de Lincoln. 
eso, además, la naturaleza funciona como una fuente de conocimiento: "una salida de sol le revela más que el mejor libro" (O.C. 25: 270).

Las ideas fundamentales del trascendentalismo que conducen al concepto de hombre natural ingresaron en la obra de Martí por la pronta, amplia y profunda lectura de la obra de Emerson, a través de sus traducciones y, finalmente, por el contacto estrecho con la obra poética de Walt Whitman, lo que permite una interesante triangulación de los textos de los tres escritores: Emerson, Whitman y Martí.

\section{BIBLIOGRAFÍA}

ALCORIZA, Javier y Antonio LASTRA.

2004 "Introducción", en Ralph W. Emerson. La conducta de la vida. Valencia: Pre-Textos, pp. 9-23.

BALLÓN, José.

1986 Autonomía cultural americana: Emerson y Martí. Madrid: Pliegos.

2013 Martí y Dario ante América y Europa. Textos y contextos contrarios. México: Universidad Nacional Autónoma de México.

CAIRO, Ana.

2003 José Martí y la novela de la cultura cubana. Santiago de Compostela: Universidad.

CAVELL, Stanley.

2002 En busca de lo ordinario. Líneas del escepticismo y romanticismo. Valencia: Cátedra.

CHÁvEZ, Félix Ernesto.

2001 "Whitman por Martí: Análisis de una confluencia", Anuario del Centro de Estudios Martianos, $\mathrm{n}^{\circ}$ 24, 2001, pp. 158-167.

CRUZ, Mary.

1978 "Centenario de 'El poeta Walt Whitman"', Anuario del Centro de Estudios Martianos, $\mathrm{n}^{\circ}$ 10, 1978, pp. 136-158.

1982 "Emerson por Martí", Anuario del Centro de Estudios Martianos, $\mathrm{n}^{\mathrm{o}} 5,1982$, pp. 78-101.

1995-1996 “¿Tradujo Martí Leaves of Grass?”, Anuario del Centro de Estudios Martianos, $\mathrm{n}^{\mathrm{o}} 18,1995-1996, \mathrm{pp} .125-131$.

1988 "Una de las más sorprendentes creaciones martianas: El poeta Walt Whitman", Anuario del Centro de Estudios Martianos, $\mathrm{n}^{\mathrm{o}} 11$, 1988, pp. 130-141.

1983 "Versión martiana de Leaves of Grass: cotejo y análisis", Revista de Literatura Cubana, $\mathrm{n}^{\mathrm{o}}$ 1, 1983, pp. 6-29. 
EMERSON, Ralph Waldo.

2009 Obra ensayística. Traducción y prólogo de Carlos Jiménez Arribas. Tenerife-Valencia: Artemisa.

ETTE, Ottmar y Titus HEYDENREICH (eds.).

1995 José Martí 1895/1995: literatura-política-filosofía-estética. Frankfurt am Main: Vervuert Verlag.

FORNET-BETANCOURT, Raúl.

1995 "José Martí y la filosofía", en Ottmar Ette y Titus Heydenreich (eds.). José Martí 1895/1995: literatura-política-filosofia-estética. Frankfurt am Main: Vervuert Verlag, pp. 43-55.

FOUNTAIN, Anne.

2003a "Autores estadounidenses asumidos por Martí", en Roberto Fernández Retamar y Pedro Pablo Rodríguez (coords.). José Marti en los Estados Unidos. Periodismo de 1881 a 1892. Edición crítica. Madrid: Conaculta-Fondo de Cultura Económica.

2003b José Martí and U.S. Writers. Gainsville: University Press of Florida.

2012 "Martí, Emerson y la naturaleza", Anuario del Centro de Estudios Martianos, $\mathrm{n}^{\mathrm{o}} 35$, pp. 112-115.

GuADARRAMA GONZÁLEZ, Pablo.

1995 "Humanismo práctico y desalienación en José Marti', en Ottmar Ette y Titus Heydenreich (eds.). José Martí 1895/1995: literatura-politica-filosofía-estética. Frankfurt am Main: Vervuert Verlag, pp. 103-116.

2014 José Martí: humanismo práctico y latinoamericanista. Santa Clara: Capiro.

JIMÉNEZ ARRIBAS, Carlos.

2009 "Prólogo", en Ralph Waldo Emerson. Obra ensayística. TenerifeValencia: Artemisa, pp. 7-34.

LACOUE-LABARTHE, Philippe y Jean-Luc NANCY.

2012 El absoluto literario. Teoría de la literatura del romanticismo alemán. Buenos Aires: Eterna Cadencia.

LIZASO, Félix.

1954 "Emerson visto por Martí", Humanismo, no 23 (septiembre 1954), pp. 31-38.

MAÑACH, Jorge.

1995 [1929] "El pensador en Martí,, en José Martí. El presidio político en Cuba. Último Diario y otros textos. Buenos Aires: Biblos, pp. 189-194. 
MORÁN, Francisco.

2014 José Martí, la justicia infinita. Notas sobre ética y otredad en la escritura martiana (1875-1894). Madrid: Verbum.

MARTí, José.

1991 Obras completas. (27 Tomos). La Habana: Editorial de Ciencias Sociales.

2010-2015 Obras completas. Edición crítica (25 tomos). La Habana: Centro de Estudios Martianos.

PAMPÍN, María Fernanda.

2014 "La idea de naturaleza y el discurso trascendentalista en Ismaelillo y en La Edad de Oro de José Martí", en Hernán Biscayart (comp.). Lecturas de travesía. Literatura latinoamericana. Buenos Aires: NJ Editor, pp. 61-71.

2015a "Entre lo propio y lo ajeno: El lugar de las tradiciones. El entrelugar del pensamiento martiano", en Guadalupe Silva y María Fernanda Pampín (comps.). Literaturas caribeñas. Debates, reescrituras, tradiciones. Buenos Aires: Facultad de Filosofía y Letras, Universidad de Buenos Aires, pp. 95-121.

2015b "José Martí y la tradición. Redes intelectuales y literatura cubana en el siglo XIX", en Celina Manzoni (ed.). Poéticas y politicas de la representación en la literatura latinoamericana. Buenos Aires: Corregidor, pp. 19-40.

2015c "Modernidad y latinoamericanismo. Los ensayos de Ángel Rama", en Ángel Rama. Martí: modernidad y latinoamericanismo. Caracas: Biblioteca Ayacucho, pp. VII-XXX.

RAMA, Ángel.

2015a [1983] "José Martí en el eje de la modernización poética: Whitman, Lautréamont, Rimbaud", en Martí: modernidad y latinoamericanismo. María Fernanda Pampín (sel. y presentación). Caracas: Biblioteca Ayacucho, pp. 192-232.

2015b [1971] "La dialéctica de la modernidad en José Martí", en Martí: modernidad y latinoamericanismo. María Fernanda Pampín (sel. y presentación). Caracas: Biblioteca Ayacucho, pp. 3-104.

VARONA, Enrique José.

1936 [1884] "Emerson”, en Literatura 1. Estudios y conferencias. Elías Entralgo, Medardo Vitier y Roberto Agramonte y Pichardo (comps.). La Habana: Cultural, pp. 287-313.

ROIG, Arturo.

2009 Teoría y crítica del pensamiento latinoamericano. Buenos Aires: Una ventana. 
SANTí, Enrico Mario.

1997 "Fortunas de Walt Whitman", en Por una politeratura. Literatura hispanoamericana e imaginación política. México: ConacultaEdiciones del Equilibrista, pp. 47-71.

SANTIAGO, Silviano.

2000 "El entrelugar del discurso latinoamericano", en Absurdo Brasil. Polémicas en la cultura brasileña. Adriana Amante y Florencia Garramuño (sel., trad. y pról.). Buenos Aires: Biblos, pp. 61-77.

SCHULMAN, Iván.

2001 "La mirada desde el Norte: Martí y los Estados Unidos", Anuario de Centro de Estudios Martianos, $\mathrm{n}^{\mathrm{o}}$ 24, 2001, pp. 48-64.

WHITMAN, Walt.

1997 Hojas de hierba. Ed. bilingüe. Sel., trad. y pról. de Jorge Luis Borges. Barcelona: Lumen. 